\title{
DETERMINATION OF OCCLUSAL CONNECTIONS IN PATIENTS WITH CONGENITAL CLEFT LIP AND PALATE BEFORE AND AFTER THEIR ORTHOPEDIC REHABILITATION
}

\author{
Roman Ilyk \\ Department of Orthopedic Dentistry ${ }^{1}$ \\ Markiyan Oliynyk $\bowtie$ \\ Department of orthopedic dentistry ${ }^{1}$ \\ oliynykmark@gmail.com \\ ${ }^{1}$ Danylo Halytsky Lviv National Medical University \\ 69 Pekarska str., Lviv, Ukraine, 79010
}

$\triangle$ Corresponding author

\begin{abstract}
The aim of this study was to define and analyze the reproducibility of occlusal relationships according to the results of occlusogram in jaw closure using quantitative analysis of occlusion in adult patients with congenital cleft lip and palate before and after their prosthesis with different versions of dentures and types of their constructive features.

Materials and methods. The study was conducted on 37 patients with congenital cleft lip and palate, 11 (29.73\%) of whom had right-sided clefts, $11(29.73 \%)$ - left-sided and 15 (40.54\%) - bilateral.

The number of occlusal contact points was measured for all patients before the treatment and after the orthopaedic rehabilitation.

Research results. Significant differences were found between the number of occlusal contact points before (unusually small number) and after orthopaedic treatment (significant increase), regardless of the type of cleft $(p<0.001)$. Such conditions in the oral cavity significantly complicate the tactics of orthopaedic rehabilitation, which affects the need to find more complex options for combinations of fixed and removable orthopaedic structures.

Conclusion. Based on the conditions and objectives of this study, the application of the basic principles of a multidisciplinary approach determine the possibility of rehabilitation of such patients by orthopedic methods by making different versions of orthopedic structures. Adequate and high-quality prosthesis for defects and deformations of the teeth rows and occlusion in patients with CCLP leads to improved occlusal relationships and increase in the number of occlusal contact points.

Keywords: congenital cleft lip and palate, dental anomalies, occlusogram, occlusal contact points, occlusal relationships.

\section{Introduction}

Congenital cleft lip and palate (CCLP) ranks second in the structure of antenatal injuries and are among the most severe malformations of the maxillofacial area, which leads to significant functional and aesthetic disorders $[1,2]$. These defects arise in about 0.82-2.1 per 1000 live born babies in different countries of Europe and North America [3, 4]. During the first decade of the 21 st century in many countries around the world there is an increase in the frequency of births of children with cleft lip and palate $[5,6]$.

Rehabilitation of these patients begins in childhood, continues to adulthood, and is one of the most difficult problems of modern orthopaedic dentistry. One of the key points of this multi-stage process is the diagnostics of occlusal relationships before and after the prosthetic treatment $[7,8]$.

Presently, the objective criterion for evaluation of occlusion is the use of computerized occlusal analysis using T-Scan, which, however, has some reservations [9, 10]. Most methods of occlusal connections registration allow obtaining qualitative and semi-quantitative characteristics $[11,12]$. Computer programs are used to quantify the features of contact points, which may not always be affordable for patients with insufficient income, and especially for patients with pre-existing dental anomalies such as CCLP [13, 14].
\end{abstract}

DOI: $10.21303 / 2504-5679.2021 .002013$ 
The aim of this article was to determine the dependence of occlusal contact points in adult patients with CCLP before and after their prosthetics with different variants of dentures and the type of their constructive features.

\section{Materials and methods}

The study was performed during 2016 to 2021 on the basis of Lviv Dental Medical center of Danylo Halytskyi Lviv Medical University. A total of 56 patients with CCLP aged 17 to 45 years were examined, 37 patients of which underwent orthopaedic rehabilitation with various variants of orthopaedic structures, including 11 patients with right-sided CCLP (29.73\%), 11 patients with left-sided CCLP (29.73\%), and 15 bilateral patients (40.54\%).

All patients undergoing orthopaedic rehabilitation underwent occlusal contact analysis with clasp wax plates before and after orthopaedic treatment.

Ethical approval was obtained from the Bioethics Committee of Danylo Halytsky Lviv National Medical University (Record No. 4, April 23, 2018).

All patients involved in the study signed an informed consent to participate in it. All potential benefits and possible risks, associated with participation in the study, as well as the ability to withdraw from it at any time were explained to them. One copy of the consent was pro-vided to the patient. The study design complies with the Helsinki Declaration.

\subsection{Experimental procedures}

To determine the occlusal contact points and their number, the plates of clasp wax (clasp wax-02) with a thickness of $0.3 \mathrm{~mm}$ were used. Occlusal contact points were determined before treatment and after completion of orthopaedic treatment (Fig. 1, a, b).

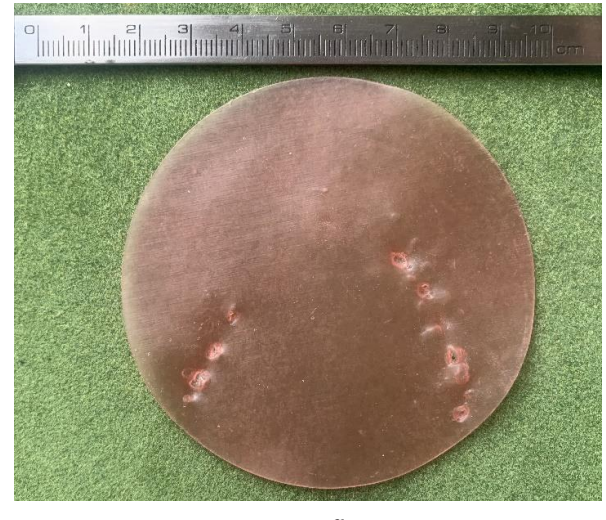

$a$

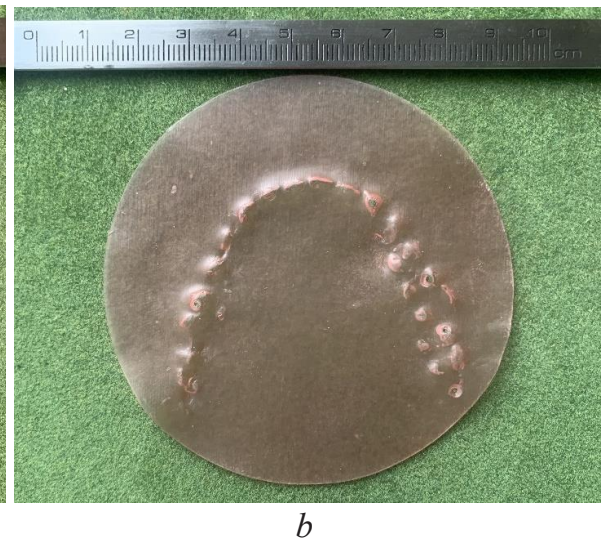

Fig. 1. Occlusal contact points: $a$ - before the treatment; $b$-after the treatment

The quantitative values of occlusal contact points were calculated both by the number of contact points of individual teeth and by the total number of contact points determined on the wax plate (teeth contacts were recorded by the available perforations on it).

Statistical processing of the study results was performed using the methods of variation statistics, the calculations were performed in the computer program SPSS software (version 13.0, SPSS; Chicago, IL). Student's parametric t-test was used to assess the probability of differences between indicators and statistical comparison of data groups and ANOVA's analysis of variance.

\section{Results}

In the process of orthopaedic rehabilitation of adult patients with CCLP after surgery, both fixed (Fig. 2, $\boldsymbol{a}, \boldsymbol{b}, \boldsymbol{c}$ ) and removable structures (Fig. 3, $\boldsymbol{a}, \boldsymbol{b}, \boldsymbol{c}$ ) were used.

The results of determining the occlusal contact points of patients with CCLP before and after the orthopaedic treatment, depending on the design of prostheses are given in Table $\mathbf{1}$ and Fig. 4. 


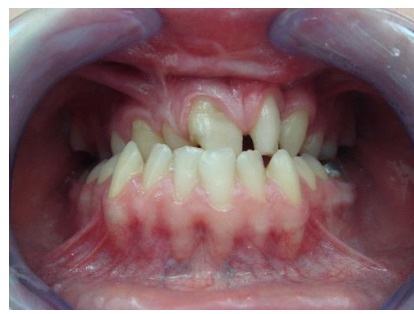

$a$

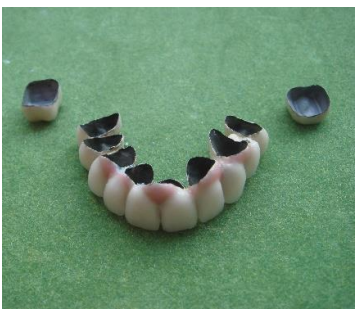

$b$

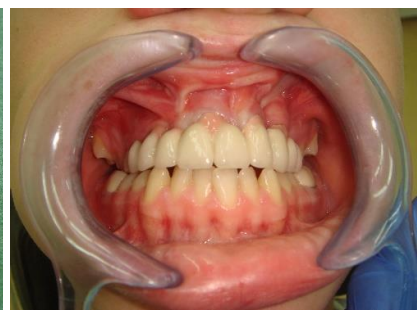

C

Fig. 2. Patient K. A.: $a$ - view in the oral cavity before the treatment; $b$ - fixed orthopaedic construction; $c$ - view in the oral cavity after the treatment

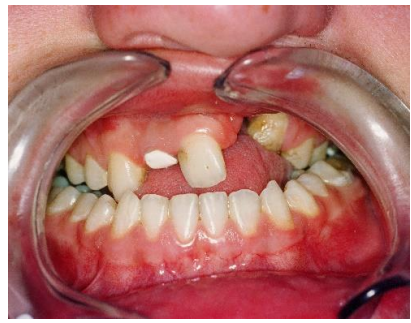

$a$

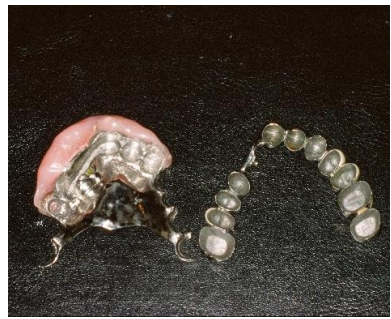

$b$

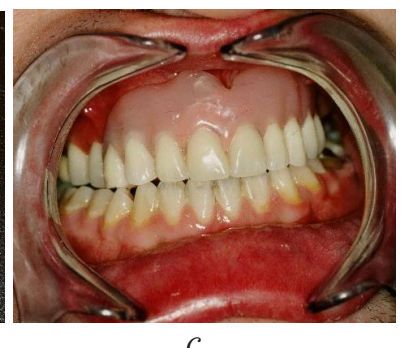

c

Fig. 3. Patient T. V.: $a$ - view in the oral cavity before the treatment;

$b$ - removable orthopaedic construction; $c$ - view in the oral cavity after the treatment

\section{Table 1}

The results of determining the occlusal connections of patients with CCLP before and after the orthopaedic treatment depending on the design of prostheses

\begin{tabular}{|c|c|c|c|c|c|c|}
\hline \multirow{3}{*}{$\begin{array}{c}\text { Stage of } \\
\text { treatment }\end{array}$} & \multicolumn{3}{|c|}{ Fixed denture structures } & \multicolumn{3}{|c|}{ Removable dentures } \\
\hline & $N$ & $\begin{array}{c}\text { Number of teeth } \\
\text { in contact }\end{array}$ & $\begin{array}{c}\begin{array}{c}\text { Number of contact } \\
\text { points }\end{array} \\
\end{array}$ & $N$ & $\begin{array}{c}\text { Number of teeth } \\
\text { in contact }\end{array}$ & $\begin{array}{c}\text { Number of contact } \\
\text { points }\end{array}$ \\
\hline & & $\mathbf{M} \pm \mathbf{S D}$ & $\mathbf{M} \pm \mathbf{S D}$ & & $\mathbf{M} \pm \mathbf{S D}$ & $\mathbf{M} \pm \mathbf{S D}$ \\
\hline Before & 27 & $6.07 \pm 0.43$ & $9.92 \pm 0.65$ & 10 & $5.2 \pm 0.58$ & $8.4 \pm 0.67$ \\
\hline After & 27 & $13.11 \pm 0.15$ & $24.59 \pm 0.59$ & 10 & $14.7 \pm 0.38$ & $26.6 \pm 1.04$ \\
\hline$P$ value & & $<0.001^{*}$ & $<0.001^{*}$ & & $<0.001^{*}$ & $<0.001 *$ \\
\hline ANOVA & & $<0.001^{*}$ & $<0.001^{*}$ & & $<0.001^{*}$ & $<0.001^{*}$ \\
\hline
\end{tabular}

Note: $N$-number of patients; $M$-mean; $S D$-standard deviation; $P$ - probability level; 2 -sided; ${ }^{*}$ - significantly different $(p<0.05)$

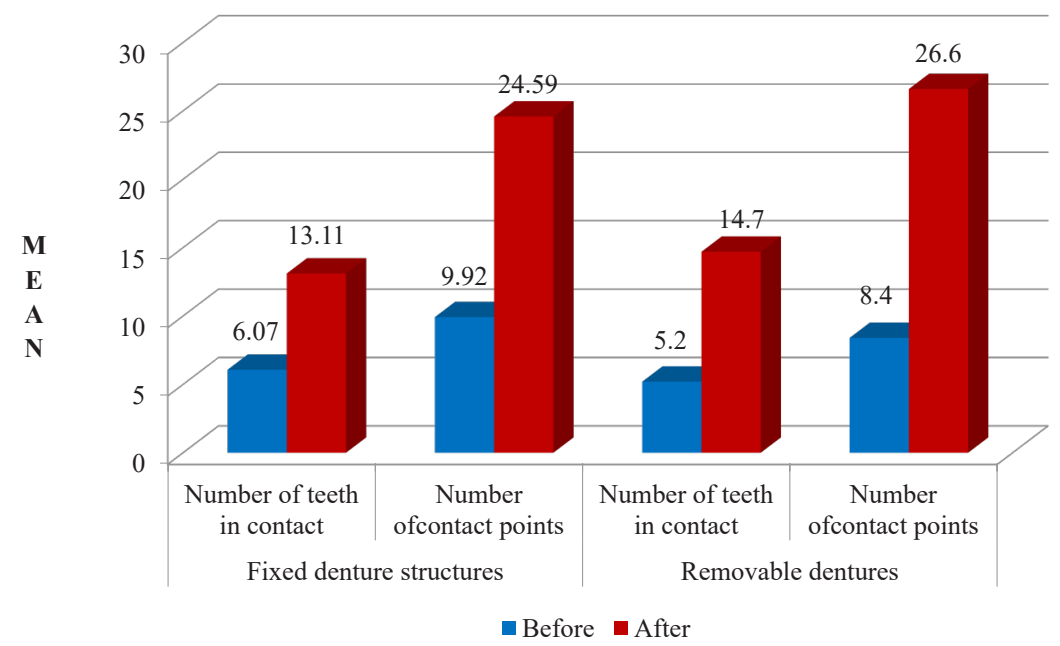

Fig. 4. The results of determining the occlusal connections of patients with CCLP before and after the orthopaedic treatment depending on the design of prostheses 
As can be seen from the presented data (Table 1 and Fig. 4) it is determined that if the number of occlusal contact points during prosthetics with fixed denture structures before the treatment was only $6.07 \pm 0.43$ tooth contacts, then after the treatment it reached $13.11 \pm 0.15$ tooth contacts $(p<0.001)$.

Similarly, the total number of contact points increased from $9.92 \pm 0.65$ before the treatment to $24.59 \pm 0.59$ after the treatment $(p<0.001)$.

When using removable dentures, it was determined that if before the treatment the number of contact teeth was only $5.2 \pm 0.58$, then after the treatment it reached $14.7 \pm 0.38$ teeth $(p<0.001)$, and the total of contact points in the number of $8.4 \pm 0.67$ before treatment increased to $26.6 \pm 1.04(p<0.001)$ (Table 1 and Fig. 4).

Given that the type of non-union itself (left, right, bilateral) may affect the quality of the orthopaedic structure, especially the occlusal ratio of structural elements of prostheses, we evaluated the existing occlusal connections before and after the orthopaedic treatment depending on the type of nonunion (Table 2 and Fig. 5).

Table 2

The results of determining the occlusal connections of patients with CCLP before and after the orthopaedic treatment depending on the type of nonunion

\begin{tabular}{|c|c|c|c|c|c|c|c|c|c|}
\hline \multirow{3}{*}{$\begin{array}{c}\text { Stage } \\
\text { of treat- } \\
\text { ment }\end{array}$} & \multicolumn{3}{|c|}{ Left-sided CCLP } & \multicolumn{3}{|c|}{ Right-sided CCLP } & \multicolumn{3}{|c|}{ Bilateral CCLP } \\
\hline & \multirow[t]{2}{*}{$N$} & $\begin{array}{l}\text { Number } \\
\text { of teeth in } \\
\text { contact }\end{array}$ & $\begin{array}{c}\text { Number } \\
\text { of contact } \\
\text { points }\end{array}$ & \multirow[t]{2}{*}{$N$} & $\begin{array}{l}\text { Number } \\
\text { of teeth in } \\
\text { contact }\end{array}$ & $\begin{array}{c}\text { Number } \\
\text { of contact } \\
\text { points }\end{array}$ & \multirow[t]{2}{*}{$N$} & $\begin{array}{l}\text { Number } \\
\text { of teeth in } \\
\text { contact }\end{array}$ & $\begin{array}{c}\text { Number } \\
\text { of contact } \\
\text { points }\end{array}$ \\
\hline & & $\mathbf{M} \pm \mathbf{S D}$ & $\mathbf{M} \pm \mathbf{S D}$ & & $\mathbf{M} \pm \mathbf{S D}$ & $\mathbf{M} \pm \mathbf{S D}$ & & $\mathbf{M} \pm \mathbf{S D}$ & $\mathbf{M} \pm \mathbf{S D}$ \\
\hline Before* & 11 & $5.72 \pm 0.6$ & $8.54 \pm 0.84$ & 11 & $6.09 \pm 0.57$ & $10.09 \pm 0.91$ & 15 & $5.73 \pm 0.68$ & $9.8 \pm 0.94$ \\
\hline After** & 11 & $14 \pm 0.37$ & $25 \pm 1.28$ & 11 & $13.81 \pm 0.27$ & $25.36 \pm 0.76$ & 15 & $13.86 \pm 0.28$ & $25.06 \pm 0.82$ \\
\hline \multicolumn{2}{|c|}{$P$ value } & $<0.001^{*}$ & $<0.001^{*}$ & & $<0.001 *$ & $<0.001^{*}$ & & $<0.001^{*}$ & $<0.001^{*}$ \\
\hline \multicolumn{2}{|c|}{ ANOVA } & $<0.001^{*}$ & $<0.001^{*}$ & & $<0.001^{*}$ & $<0.001^{*}$ & & $<0.001^{*}$ & $<0.001^{*}$ \\
\hline
\end{tabular}

Note: $N$-number of patients; $M$-mean; $S D$ - standard deviation; $P$ - probability level 2 -sided; $*$ - significantly different $(P<0.05)$

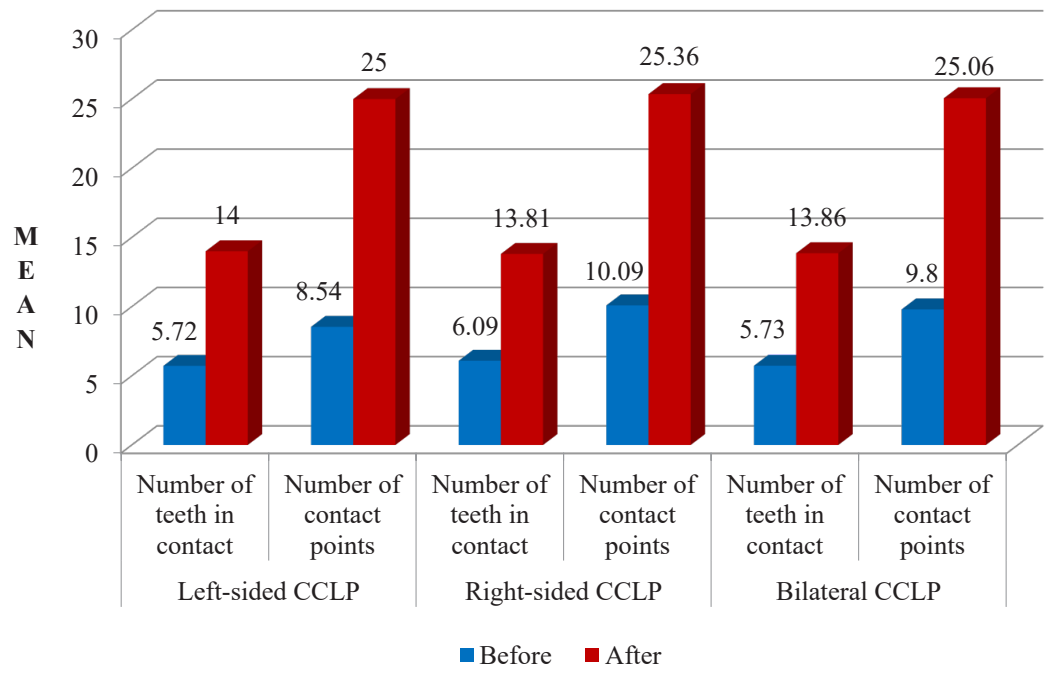

Fig. 5. The results of determining the occlusal connections of patients with CCLP before the orthopaedic treatment depending on the type of nonunion

It was determined that in left-sided CCLP the number of teeth that came into contact in the occlusion before the treatment was $5.72 \pm 0.6$, and after the orthopaedic treatment became $14 \pm 0.37(p<0.001)$. 
The total of contact points before the treatment was equal to $8.54 \pm 0.84$, after the treatment it came to $25 \pm 1.28(p<0.001)$.

In right-sided CCLP, the number of teeth in contact before the treatment was $6.09 \pm 0.57$, and after the treatment it became $13.81 \pm 0.27(p<0.001)$. The total of occlusal connections before the treatment was equal to $10.09 \pm 0.91$, and after the treatment it came to $25.36 \pm 0.76(p<0.001)$.

In bilateral CCLP, the number of teeth that were in occlusal contact before the treatment was $5.73 \pm 0.68$, and after the orthopaedic treatment it changed into $13.81 \pm 0.27(p<0.001)$.

The number of general occlusal connections in this study group before the treatment was $9.8 \pm 0.94$, after the orthopaedic treatment they counted 25.06 $\pm 0.82(p<0.001)$.

\section{Discussion}

Taking into account the conditions and objectives of this research, the decisions on the type of constructions were based on a thorough clinical examination of the patient.

The attention was payed to the state of his dental system and the functional state of the oral cavity (teeth, periodontium, occlusion, jaw ratio, bone system, masticatory muscles etc.) using the basic principles of a multidisciplinary approach $[15,16]$.

Noteworthy is the unusually small number of teeth in contact with each other in all types of nonunion, regardless of their type. It varies from 5.7 in left-sided and bilateral nonunion to 6.09 in the right-sided one $[17,18]$.

This is obviously associated with significant deformations of the dental complex of patients, and with the loss of teeth because of inadequacy of applied treatment and prevention measures at all stages of prosthetic rehabilitation, as well as possible complications in the process of treatment $[19,20]$.

Such conditions in the oral cavity $[21,22]$ significantly complicate the tactics of orthopaedic rehabilitation, which affects the need to find more complex options for combinations of fixed and removable orthopaedic structures [23, 24].

Study limitations. In this study, we did not conduct a qualitative analysis due to the lack of financial availability of the best tools for the study; we could not establish and evaluate all the parameters of dynamic occlusion.

Prospects for the further research. Further research is planned using computerized occlusion analysis to study not only quantitative but also qualitative occlusion analysis in adult patients with CCLP to improve approaches to prosthetics in such patients.

\section{Conclusion}

1. An extremely small number of occlusal connections between the upper and lower dentitions in adult patients with congenital cleft lip and palate after completion of postoperative interventions was defined, as a result of significant deformations of the upper jaw and tooth loss (When using removable dentures, before the treatment the number of contact teeth was $5.2 \pm 0.58(p<0.001)$, and the total of contact points $8.4 \pm 0.67$ before treatment $(p<0.001))$.

2 . The possibility of rehabilitation of such patients was by orthopaedic methods was found, making different versions of orthopaedic structures for occlusive-functional and final rehabilitation, as one of the ways to improve the quality of life of such patients.

3. Adequate and high-quality prosthesis for defects and deformations of the teeth rows and occlusion in patients with CCLP leads to improved occlusal relationships and increase in the number of occlusal contact points (when using removable dentures, after the treatment the number of contact teeth was $14.7 \pm 0.38$ teeth $(p<0.001)$, and the total of contact points after treatment increased to $26.6 \pm 1.04(p<0.001)$.

\section{Conflict of interests}

The authors declare that they have no conflicts of interest.

\section{Financing}

The study was performed without financial support. 


\section{Acknowledgments}

We are grateful to the administration of the Lviv Dental Medical center of Danylo Halytskyi Lviv Medical University and to the head of the center - Volodymyr R. Shybinskyi - Ph.D., associate professor, and Victor S. Kukhta - Ph.D., associate professor, the Head of the department of Prosthetic Dentistry of Danylo Halytskyi Lviv Medical University

\section{References}

[1] Mossey, P. A., Little, J., Munger, R. G., Dixon, M. J., Shaw, W. C. (2009). Cleft lip and palate. The Lancet, 374 (9703), 1773-1785. doi: http://doi.org/10.1016/s0140-6736(09)60695-4

[2] Berg, E., Haaland, Ø. A., Feragen, K. B., Filip, C., Vindenes, H. A., Moster, D. et. al. (2016). Health Status Among Adults Born With an Oral Cleft in Norway. JAMA Pediatrics, 170 (11), 1063-1070. doi: http://doi.org/10.1001/jamapediatrics.2016.1925

[3] Matthews, J. L. K., Oddone-Paolucci, E., Harrop, R. A. (2015). The Epidemiology of Cleft Lip and Palate in Canada, 1998 to 2007. The Cleft Palate-Craniofacial Journal, 52 (4), 417-424. doi: http://doi.org/10.1597/14-047

[4] Kati, F. (2018) Cleft lip and palate: review article. World Journal of Pharmaceutical and Medical Research, 4, 155-163. Available at: https://www.researchgate.net/publication/331304698

[5] Allori, A. C., Mulliken, J. B., Meara, J. G., Shusterman, S., Marcus, J. R. (2017). Classification of Cleft Lip/Palate: Then and Now. The Cleft Palate-Craniofacial Journal, 54 (2), 175-188. doi: http://doi.org/10.1597/14-080

[6] Savichuk, N. O., Parpaley, E. A., Trubka, I. A., Timokhina, V. A., Korniienko, L. V., Sorochenko, N. A (2015). Principles of Dental Care of Children with Congenital Malformations of the Maxillofacial Area during the Treatment and Rehabilitation. Bulettin of problems in biology and medicine, 2 (2), 206-211.

[7] Matos, D. A. D., Teixeira, M. L., Pinto, J. H. N., Lopes, J. F. S., Dalben, G. da S. (2006). Pattern of disocclusion in patients with complete cleft lip and palate. Journal of Applied Oral Science, 14 (3), 157-161. doi: http://doi.org/10.1590/ s1678-77572006000300002

[8] Razdan, S., Bhat, V., Reddy, H., Shetty, S. (2021). Evaluation of bite force in patients with cleft lip and palate and its comparison with normal patients. Archives of Medicine and Health Sciences, 9 (1), 44-49. doi: http://doi.org/10.4103/ amhs.amhs_235_20

[9] Ibraheem, E. M., ElGabry, H. S. (2021). Effect of mandibular complete dentures relining on occlusal force distribution using T-scan system. Bulletin of the National Research Centre, 45 (1). doi: http://doi.org/10.1186/s42269-021-00537-7

[10] Fedorova, O. V. (2017). Use of computer analysis of occlusal contacts in orthopedic patients with secondary deformities of dentition (literature review). Ukrainian Dental Almanac, 3, 49-52.

[11] Kerstein, R. B. (Ed.) (2015). Handbook of Research on Computerized Occlusal Analysis Technology Application in Dental Medicine. IGI Global. doi: http://doi.org/10.4018/978-1-4666-6587-3

[12] Lykhota, K. (2018). Evaluation of the dynamics of occlusion ratio during orthodontic treatment of patients with permanent bite. Ukrainian Dental Almanac, 4, 50-54. doi: http://doi.org/10.31718/2409-0255.4.2018.09

[13] Zhehulovych, Z. Ye., Nespriadko, V. P., Shynchukovskyi, I. A. (2015). Use of Quantitative Dental Occlusion Index in Clinical Practice. Galician Medical Journal, 22 (4 (1)), 19-23.

[14] De Oliveira, R. L. B., de Santana Santos, T., de Almeida Teixeira, J. L., Martins-Filho, P. R. S., da Silva, L. C. F. (2015). Health-Related Quality of Life Patients With a Cleft Lip and/or Palate. Journal of Craniofacial Surgery, 26 (8), $2315-2319$. doi: http://doi.org/10.1097/scs.0000000000001992

[15] DeQueiroz Herkrath, A. P. C., Herkrath, F. J., Rebelo, M. A. B., Vettore, M. V. (2018). Determinants of health-related and oral health-related quality of life in adults with orofacial clefts: A cross-sectional study. Cleft Palate-Craniofacial Journal, 55 (9), 1244-1257. doi: http://doi.org/10.1177/1055665618763377

[16] Moi, A. L., Gjengedal, H., Lybak, K., Vindenes, H. (2020). «I smile, but Without Showing My Teeth»: The Lived Experience of Cleft, Lip, and Palate in Adults. The Cleft Palate-Craniofacial Journal, 57 (7), 799-807. doi: http://doi.org/ $10.1177 / 1055665620922096$

[17] Sultan, J., Memon, M. R., Kashif, M., Kashif, N. (2015). General complications in patients wearing polymethylmethacrylate heat cure acrylic resin partial removable dental protheses. Pakistan Oral and Dental Journal, 35 (2), 339-342.

[18] Bilhan, H., Geckili, O., Ergin, S., Erdogan, O., Ates, G. (2013). Evaluation of satisfaction and complications in patients with existing complete dentures. Journal of Oral Science, 55 (1), 29-37. doi: http://doi.org/10.2334/josnusd.55.29

[19] Owall, B. (2016). Precision attachment retained removable partial dentures: 1. Technical long-term study. The International Journal of Prosthodontics, 4 (3), 249-257. Available at: http://www.ncbi.nlm.nih.gov/pubmed/1810316

[20] Pisek, A., Pitiphat, W., Chowchuen, B., Pradubwong, S. (2014). Oral health status and oral impacts on quality of life in early adolescent cleft patients. Journal of the Medical Association of Thailand, 97 Suppl 10, S7-S16. 
[21] Worth, V., Perry, R., Ireland, T., Wills, A. K., Sandy, J., Ness, A. (2017). Are people with an orofacial cleft at a higher risk of dental caries? A systematic review and meta-analysis. British Dental Journal, 223 (1), 37-47. doi: http://doi.org/10.1038/ sj.bdj.2017.581

[22] Veiga, K. A., Porto, A. N., Matos, F. Z., deBrito, P. C., Borges, Á. H., Volpato, L. E., Aranha, A. M. (2017). Caries Experience and Periodontal Status in Children and Adolescents with Cleft Lip and Palate. Pediatric dentistry, 39 (2), 139-144.

[23] Makieiev, V. F., Oliynyk, A. Y. (2017). Orthopedic Rehabilitation of Patients with Congenital Clefts of the Upper Lip and Palate by Different Kinds of Prosthetic Constructions Using Own Dentition Deformations Visualization Method to Assess their Severity. Novyny stomatolohii, 3, 43-50.

[24] Makieiev, V. F. (2013). Ortopedychni metody likuvannia khvorykh iz vrodzhenymy nezroshchenniamy verkhnoi huby ta pidnebinnia. Lviv: Kvart, 164.

Received date 10.08.2021

(C) The Author(s) 2021

Accepted date 14.09.2021

This is an open access article

Published date 30.09.2021 under the Creative Commons CC BY license

How to cite: Ilyk, R., Oliynyk, M. (2021). Determination of occlusal connections in patients with congenital cleft lip and palate before and after their orthopedic rehabilitation. EUREKA: Health Sciences, 5, 34-40. doi: http://doi.org/10.21303/ 2504-5679.2021.002013 